\title{
Syntheses and Ring-Opening Polymerizations of 2, 3- and 2, 5-Dimethyl-7-Oxabicyclo[2.2.1]heptanes
}

\author{
Takeo Saegusa, ${ }^{*}$ Masatoshi Motor, ${ }^{* *}$ Hiroshi Suda, ${ }^{* *}$ \\ Hideaki KaSAI, ${ }^{* *}$ and Akihiko UeYAMA** \\ *Department of Synthetic Chemistry, Faculty of Engineering, Kyoto University, \\ Yoshidahon-machi, Sakyo-ku, Kyoto 606, Japan. \\ **Department of Industrial Chemistry, Faculty of Technology \\ Kanazawa University, Kodatsuno, Kanazawa 920, Japan.
}

(Received February 17, 1978)

\begin{abstract}
New bicyclic ethers, 2,3- and 2,5-dimethyl-7-oxabicyclo[2.2.1]heptanes were synthesized from 2,3- and 2,5-dimethylphenols as starting materials. Each of them was separated by fractional distillation and preparative gas chromatography into the corresponding exo,exo-, endo,exo-, and endo,endo-isomers. Ring-opening polymerizations of these isomeric monomers were carried out in $\mathrm{CH}_{2} \mathrm{Cl}_{2}$ using cationic initiators such as $\mathrm{BF}_{3}$-tetrahydrofuran (THF) complex -epichlorohydrin (ECH), $\mathrm{SnCl}_{4}-\mathrm{ECH}, \mathrm{SbCl}_{5}-\mathrm{ECH}$, and $\mathrm{FeCl}_{3}-\mathrm{SOCl}_{2}$ systems. The $\mathrm{SbCl}_{5}-\mathrm{ECH}$ catalyst system brought about high monomer conversions, but it induced a chain-transfer reaction during the polymerization. The exo,exo- and endo,exo2,3-dimethyl monomers (1a and 1b) yielded white powdery polymers in yields of 58 and $63 \%$, respectively, using the $\mathrm{SbCl}_{5}-\mathrm{ECH}$ system. NMR spectroscopic analysis of poly(1) showed that it contained a chair-formed trans,trans,trans-1,2,3,4-tetrasubstituted cyclohexane ring in its monomeric unit. Both exo,exo- and endo,endo-2,5-dimethyl monomers ( $2 \mathrm{a}$ and $2 \mathrm{c}$ ) yielded grease-like polymers in 16 and $17-\%$ yields, and its endo,exo-isomer (2b) yielded a highly crystalline polymer, which was insoluble in the usual organic solvents, in $26-\%$ yield using $\mathrm{BF}_{3}-\mathrm{ECH}$. A monomeric unit in poly(2b) was assumed to be trans,cis,trans-1,2,4,5-tetrasubstituted cyclohexane. In the polymerization of the monomers $\mathbf{1 b}$ and $\mathbf{2 b}$, it has been shown that the monomer attacks the propagating end at the bridgehead carbon in position 4 (C-4), but not in position 1 (C-1). Nucleophilicities of the monomers $\mathbf{2 a}$ and $\mathbf{2} \mathbf{b}$ were compared based on their copolymerizations with the exo-monomethyl analogue (3a). The exo-methyl group relative to the endo-methyl group tends to lower the monomer nucleophilicity. The polymer yield is controlled by three factors; the steric crowding around the bridgehead carbon due to the methyl group, the nucleophilicity, and the ring strain of the monomer.
\end{abstract}

KEY WORDS Cationic Ring-Opening Polymerization / Bicyclic Ethers / Stereochemistry / Copolymerization /

This paper describes syntheses of six new bicyclic ethers and their ring-opening polymerizations by cationic initiators. These new ether compounds are the exo,exo-, endo,exo-, and endo,endo-isomers of the 2,3- and 2,5-dimethyl-7-oxabicyclo[2.2.1]heptanes, as shown below:

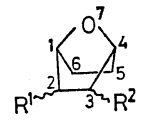

1a, $\mathrm{R}^{1}=\mathrm{R}^{2}=$ exo- $\mathrm{CH}_{3}$

1b, $\mathrm{R}^{1}=$ endo- $\mathrm{CH}_{3}, \mathrm{R}^{2}=$ exo $-\mathrm{CH}_{3}$

1c, $\mathrm{R}^{1}=\mathrm{R}^{2}=$ endo- $\mathrm{CH}_{3}$

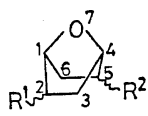

2a, $\mathrm{R}^{1}=\mathrm{R}^{2}=$ exo- $\mathrm{CH}_{3}$

2b, $\mathbf{R}^{1}=$ endo- $\mathrm{CH}_{3}, \mathrm{R}^{2}=$ exo $-\mathrm{CH}_{3}$

2c, $\mathrm{R}^{1}=\mathrm{R}^{2}=$ endo $-\mathrm{CH}_{3}$ 
Studies of the kinetics and stereochemistry of ring-opening polymerizations of exo- and endo-2methyl-7-oxabicyclo[2.2.1]heptanes (3a and $\mathbf{3 b}$ ) have been reported by Saegusa and coworkers. ${ }^{1,2,3}$ Their polymerizations can be depicted as follows

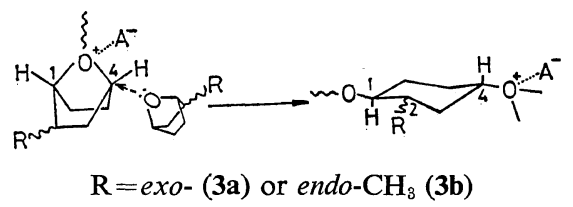

where $\mathrm{A}^{-}$is a counteranion. In a propagation step of the polymerization of these monomethyl substituted bicyclic ethers, the monomer attacks the bridgehead carbon of the oxonium end at position $4(\mathrm{C}-4)$ by $S_{N} 2$ mechanism so as to avoid the steric hindrance owing to the methyl group. A cyclohexane unit of the polymer takes a chairformed structure of 1,4-trans configuration. On the basis of the kinetic analysis of the polymerization of the monomethyl monomers by means of the phenoxyl end-capping method, it has been established that the propagation rate constant of the endo isomer (3b) was about 3 to 4 times higher than that of the exo isomer (3a). The difference of reactivity of these monomers was ascribed to the difference of their ring strains (and also the strains of their oxonium ions). In the polymerizations of the 2,3- and 2,5-dimethyl bicyclic ethers in the present study, geometric positions (exo or endo) of the two substituents in the monomers (and also their oxonium ions) will influence not only the ring strain of the monomer (and also their oxonium ions) but also the steric hindrance in the propagation process. In this process the bridgehead carbon (either $\mathrm{C}-1$ or $\mathrm{C}-4$ ) of the propagating oxonium which will be attacked by the monomer nucleophile is blocked more seriously than the bridgehead carbon in the monomethyl monomer 3a or 3b. Furthermore, the endo,exotype monomers are of interest, since in these polymerizations there will be two types of propagation processes which give different units of polyethers. The nucleophilicity of the monomer, which will be affected by both the methyl groups, is also one of the important factors of the polymerization.

Recently, Kops and Spanggaard synthesized 2,6dimethyl analogues, and polymerized the endo,exoisomer by $\mathrm{PF}_{5}$ initiator to obtain a highly crystalline polymer. ${ }^{4}$ It is also possible to discuss the relationship between the polymerization of our new bicyclic ethers and their structures; this may clarify the propagation mechanism and the monomer reactivity.

\section{RESULTS AND DISCUSSION}

Two sets of the three isomeric ethers of $1 \mathbf{a}-\mathbf{1 b}-$ $1 c$ and $2 a-2 b-2 c$ were prepared from 2,3- and 2,5-dimethylphenols as starting materials according to Scheme I:

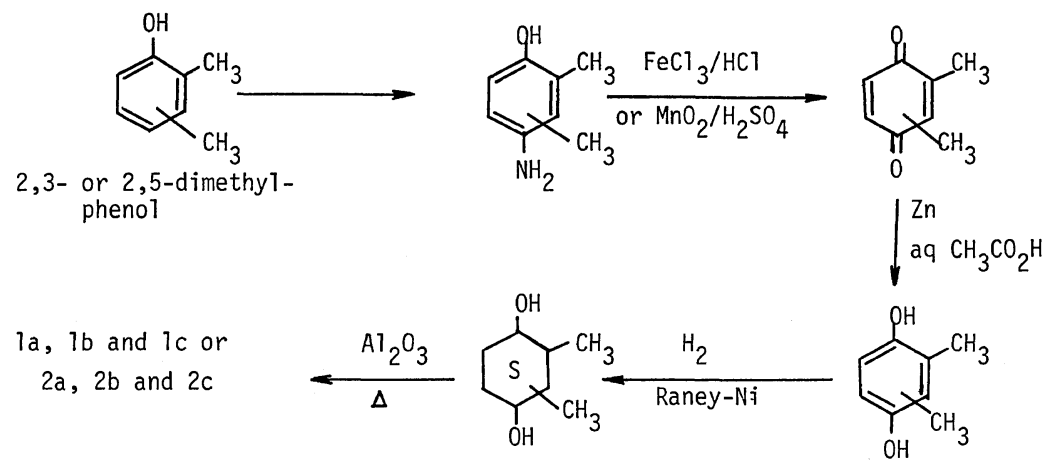

Scheme I

The yield of 2,5-dimethylbenzoquinone from 2,5dimethylphenol by oxidation using $\mathrm{FeCl}_{3}$ and hydrochloric acid was $85 \%{ }^{5}$ but that of 2,3dimethylbenzoquinone from 2,3-dimethylphenol by the same oxidant ${ }^{6}$ or $\mathrm{CrO}_{3}$ and diluted sulfuric acid $^{7}$ was not sufficient. The oxidation of the 2,3dimethyl-4-aminophenol to the corresponding benzoquinone was successfully carried out by use of 
$\mathrm{MnO}_{2}$ and sulfuric acid in a $70-\%$ yield $(62 \%$ : Arnold and $Z^{2}$ augg ${ }^{8}$ ). The benzoquinones were reduced by $\mathrm{Zn}$ powder and aqueous acetic acid to the dimethylhydroquinones according to the procedure described in the literature. ${ }^{7}$ The catalytic hydrogenation products from the hydroquinones were heated with activated alumina to give crude bicyclic ethers, $\mathbf{1 a}, \mathbf{1 b}$, and $\mathbf{1 c}$ or $\mathbf{2 a}, \mathbf{2 b}$, and $\mathbf{2 c}$ (purities above $95 \%$ ) in 11,16 , and 1.4 or 10,5 , and $3-\%$ yields (based on the hydroquinones), respectively, by fractional distillation. Further purifications by preparative gas chromatography gave monomers with purities above $99 \%$. They were identified on the basis of their elemental analyses and NMR spectra. The geometric positions of the methyl groups of these monomers were determined by NMR spectroscopy.

The NMR spectra of $\mathbf{1 a}, \mathbf{1 b}, \mathbf{1 c}, \mathbf{2 a}, \mathbf{2 b}$, and $\mathbf{2 c}$ are shown in Figures 1a, 1b, 1c, 2a, 2b, and 2c, respectively. In the spectrum of $\mathbf{2 b}$ (Figure $2 \mathrm{~b}$ ), the two doublets at $\delta 0.92$ and $0.95 \mathrm{ppm}$ are as-

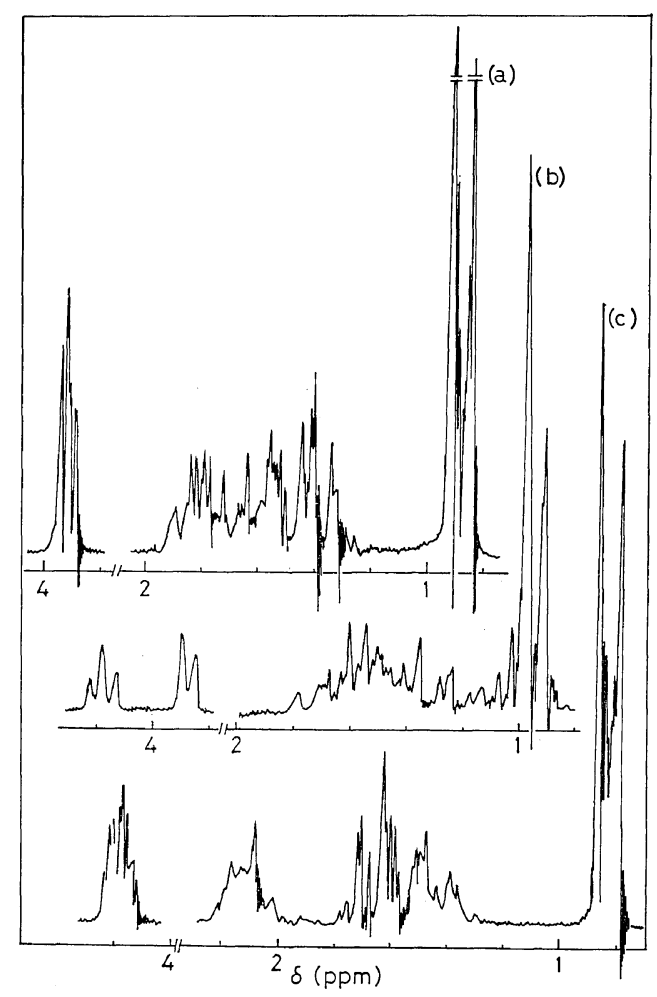

Figure 1. NMR spectra (100 MHz) of (a) 1a, (b) 1b, and (c) $1 \mathrm{c}$ in $\mathrm{CCl}_{4}$. signed to two methyl groups which are located at different geometric positions, i.e., one is at the exo and another is at the endo position. Therefore, signals due to the methyne protons at the bridgehead carbons must appear at separate chemical shifts. These, in fact, are shown at $\delta 3.87$ and $4.15 \mathrm{ppm}$ as doublet- and a triplet-like signals. The doublet can be assigned to the methyne proton at $\mathrm{C}-4$, and the triplet to tha: at $\mathrm{C}-1$ bridgehead carbon, since the NMR signals of the methyne protons at $\mathrm{C}-1$ carbons of $\mathbf{3 a}$ and $\mathbf{3 b}$ were observed as doublet- and a triplet-like signals, and the methyne proton of the exo-isomer 3a resonanced at about $0.2 \mathrm{ppm}$ higher field than that of the endo-isomer 3b. In the NMR spectra of 2a and 2c (Figures 2a and 2c), doublets at $\delta 0.92$ ppm in Figure 2a and at $\delta 0.99 \mathrm{ppm}$ in Figure 2c are assignable to the methyl groups of $\mathbf{2 a}$ and $\mathbf{2 c}$, respectively. A doublet-like signal at $\delta 3.94 \mathrm{ppm}$ in Figure 2a and a triplet-like signal at $\delta 4.10 \mathrm{ppm}$ in Figure 2c are due to methyne protons located

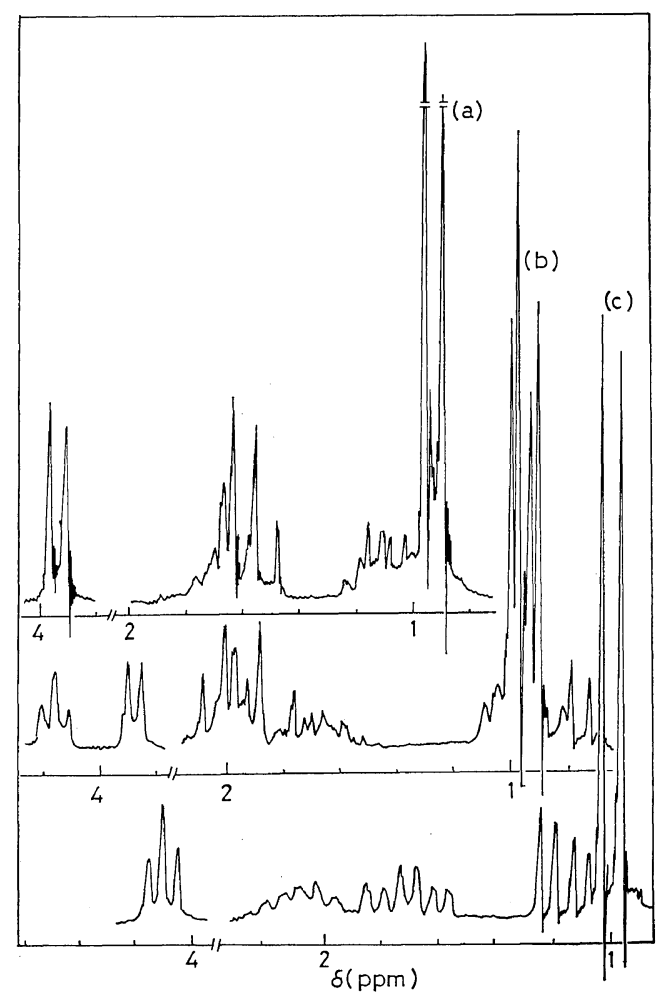

Figure 2. NMR spectra (100 MHz) of (a) $\mathbf{2 a}$, (b) $\mathbf{2 b}$, and (c) $2 \mathrm{c}$ in $\mathrm{CCl}_{4}$. 
at the bridgehead carbons of $\mathbf{2 a}$ and $\mathbf{2 c}$, respectively. From the chemical shifts and the shapes of their signals, it is concluded that 2a and 2c correspond to the exo,exo- and endo,endo-isomers, respectively.

In the spectrum of $\mathbf{1 b}$ (Figure 1b), the tripletand the doublet-like signals at $\delta 4.17$ and $3.86 \mathrm{ppm}$ are assigned to two methyne protons which are in unequivalent magnetic fields because of the presence of the endo-and exo-methyl groups. However, two doublets of the methyl groups appear not to be separated sufficiently, probably because their chemical shifts have almost no difference, as will be deduced from the cases of $\mathbf{1 a}$ and 1c. The spectra of $1 \mathrm{a}$ and 1c show the multiplet signals, which should be assigned to their methyne protons on the bridgehead carbons, at $\delta 3.91$ and $4.17 \mathrm{ppm}$, respectively. The doublet signals of the methyl groups of 1a and 1c are shown at $\delta 0.87$ and $0.80 \mathrm{ppm}$, and the difference in these chemical shifts is small.

According to Allinger's rule, ${ }^{9}$ the boiling points of these monomers will increase with increasing the number of the endo-methyl group. In the series of 2,5-dimethyl monomers, the boiling points of the crude $\mathbf{2 a}$ (exo,exo-), $\mathbf{2 b}$ (endo,exo-), and $\mathbf{2 c}$ (endo,endo-) were 146-148, 152-154, and 157$159^{\circ} \mathrm{C}$, respectively. In the 2,3-dimethyl analogues, however, the crude $\mathbf{1 b}$ (endo,exo-), 1a (exo,exo-), and 1c (endo,endo-) boiled at 150-151, 156-158, and $158-162^{\circ} \mathrm{C}$, respectively. It is interesting that 1a, with two exo-methyl groups, boils at a higher temperature than $\mathbf{1 b}$, with one exo-and one endo-methyl groups.

Results of the cationic polymerizations of 2,3and 2,5-dimethyl ether isomers in $\mathrm{CH}_{2} \mathrm{Cl}_{2}$ at -20 or $0^{\circ} \mathrm{C}$ with several catalytic systems are summarized in Table I. The monomers $\mathbf{1 a}, \mathbf{1 b}$, and $\mathbf{2 b}$ yielded white powdery polymers in fairly good yields with the $\mathrm{SbCl}_{5}$-epichlorohydrin $(\mathrm{ECH})$ system. Poly(2b) was insoluble in the usual organic solvents and highly crystalline on the basis of the X-ray diffraction diagram (Figure 3). Poly(1a) was rather soluble in hot trichloroethylene. The monomers $\mathbf{1 a}$ and $\mathbf{2 b}$ polymerized heterogeneously with deposition of polymer after about 10 minutes.

Conversions of the monomers under similar reaction conditions increased in the orders of $\mathbf{1 c} \ll \mathbf{1 a} \leq \mathbf{1 b}$ and $\mathbf{2 a} \leq \mathbf{2 c}<\mathbf{2 b}$. It should be emphasized that these conversion orders are not reflected by the order of the ring strain of these monomers; i.e., the ring strains can reasonably be assumed to increase in the orders of $\mathbf{1 a}<\mathbf{1 b}<\mathbf{1 c}$ and $\mathbf{2} \mathbf{a}<\mathbf{2} \mathbf{b}<\mathbf{2} \mathbf{c}$, since the studies of the heat of combustion of $\mathbf{3 a}$ and $\mathbf{3 b}$ revealed that the ring strain of the bicyclic ethers is increased by an endo-more than by an exo-methyl substituent. ${ }^{10}$

In addition, the conversion was affected by initiators. Of the initiators used here, the $\mathrm{SbCl}_{5}-$ $\mathrm{ECH}$ system gave the highest conversions in the polymerization of the dimethyl bicyclic ethers.

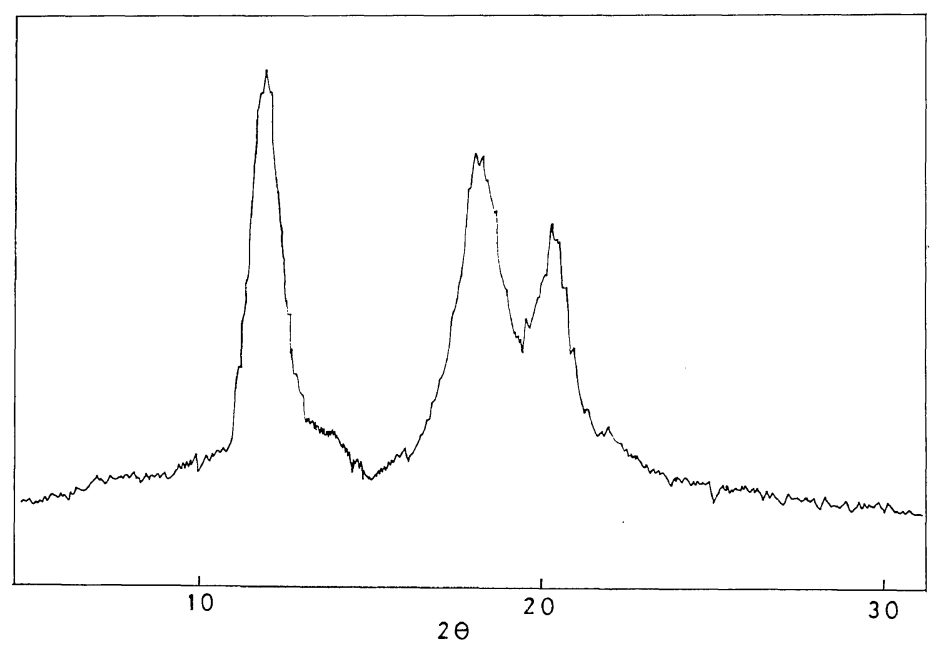

Figure 3. X-ray diffraction intensity pattern for poly(2b). 
Table I. Cationic polymerizations of 2,3- and 2,5-dimethyl7-oxabicyclo[2.2.1]heptanes in $\mathrm{CH}_{2} \mathrm{Cl}_{2}$

\begin{tabular}{|c|c|c|c|c|c|c|c|}
\hline $\begin{array}{l}\text { Monomer } \\
\text { concn, mol } l^{-1}\end{array}$ & \multicolumn{2}{|c|}{$\begin{array}{l}\text { Catalyst, } \\
\text { mol \% }\end{array}$} & $\begin{array}{l}\mathrm{ECH}, \\
\mathrm{mol} \%\end{array}$ & $\underset{{ }^{\circ} \mathrm{C}}{\text { Temp, }}$ & $\underset{\mathrm{h}}{\mathrm{Time}}$ & $\begin{array}{c}\text { Convn, } \\
\%\end{array}$ & $\bar{M}_{n}{ }^{\mathrm{a}}$ \\
\hline \multicolumn{8}{|c|}{ exo,exo-2,3-isomer (1a) } \\
\hline 1.7 & $\mathrm{SbCl}_{5}$ & 4 & 2 & -20 & 4 & 18 & \\
\hline 1.7 & $\mathrm{SbCl}_{5}$ & 4 & 2 & -22 & 94 & 58 & \\
\hline 1.5 & $\mathrm{SbCl}_{5}$ & 4 & 2 & 0 & 48 & 56 & \\
\hline \multicolumn{8}{|c|}{ endo,exo-2,3-isomer (1b) } \\
\hline 1.6 & $\mathrm{SbCl}_{5}$ & 4 & 2 & -20 & 2 & 35 & 1438 \\
\hline 1.7 & $\mathrm{SbCl}_{5}$ & 4 & 2 & -20 & 4 & 42 & $1194(3801)^{b}$ \\
\hline 1.7 & $\mathrm{SbCl}_{5}$ & 4 & 2 & -22 & 94 & 67 & 1130 \\
\hline 1.3 & $\mathrm{SbCl}_{5}$ & 4 & 4 & -20 & 2 & 46 & 1236 \\
\hline 1.6 & $\mathrm{SbCl}_{5}$ & 4 & 2 & 0 & 2 & 29 & 716 \\
\hline 1.7 & $\mathrm{SbCl}_{5}$ & 4 & 2 & 0 & 4 & 36 & 739 \\
\hline 2.3 & $\mathrm{SbCl}_{5}$ & 2 & 2 & 0 & 48 & 56 & $(1257)^{\mathrm{b}}$ \\
\hline 1.7 & $\mathrm{BF}_{3} \mathrm{THF}$ & 4 & 2 & -22 & 480 & 24 & $737(1795)^{\mathrm{b}}$ \\
\hline 1.7 & $\mathrm{BF}_{3} \mathrm{THF}$ & 4 & 2 & 0 & 4 & 16 & 876 \\
\hline 1.7 & $\mathrm{BF}_{3} \mathrm{THF}$ & 4 & 2 & 0 & 94 & 21 & 630 \\
\hline \multicolumn{8}{|c|}{ endo,endo-2,3-isomer (1c) } \\
\hline 1.7 & $\mathrm{SbCl}_{5}$ & 4 & 2 & 0 & 48 & 4 & \\
\hline \multicolumn{8}{|c|}{ exo,exo-2,5-isomer (2a) } \\
\hline 1.7 & $\mathrm{SbCl}_{5}$ & 4 & 2 & -22 & 94 & 21 & 795 \\
\hline 1.4 & $\mathrm{SbCl}_{5}$ & 4 & 2 & 0 & 72 & 28 & \\
\hline 1.4 & $\mathrm{BF}_{3} \mathrm{THF}$ & 4 & 2 & 0 & 2 & 16 & 493 \\
\hline \multicolumn{8}{|c|}{ endo,exo-2,5-isomer (2b) } \\
\hline 1.4 & $\mathrm{SbCl}_{5}$ & 1 & 2 & 0 & 72 & 29 & \\
\hline 1.4 & $\mathrm{SbCl}_{5}$ & 2 & 2 & 0 & 72 & 48 & \\
\hline 1.4 & $\mathrm{FeCl}_{3}$ & 1 & $2^{c}$ & 0 & 72 & 34 & \\
\hline 1.4 & $\mathrm{FeCl}_{3}$ & 2 & $1^{\mathrm{c}}$ & 0 & 72 & 38 & \\
\hline 1.3 & $\mathrm{SnCl}_{4}$ & 1 & 2 & 0 & 72 & 19 & \\
\hline 1.4 & $\mathrm{SnCl}_{4}$ & 2 & 2 & 0 & 72 & 21 & \\
\hline 1.4 & $\mathrm{BF}_{3} \mathrm{THF}$ & 3 & 2 & 0 & 2 & 26 & \\
\hline 1.4 & $\mathrm{BF}_{3} \mathrm{THF}$ & 1 & 2 & 0 & 72 & 18 & \\
\hline \multicolumn{8}{|c|}{ endo,endo-2,5-isomer (2c) } \\
\hline 2.8 & $\mathrm{BF}_{3} \mathrm{THF}$ & 2 & 1 & -30 & 5.5 & 5 & 636 \\
\hline 1.8 & $\mathrm{BF}_{3} \mathrm{THF}$ & 3 & 1 & 0 & 2 & 17 & 1235 \\
\hline
\end{tabular}

${ }^{a}$ Measured by vpo; solvent, $\mathrm{CHCl}_{3}$.

b Methanol-insoluble part.

c Cocatalyst, $\mathrm{SOCl}_{2}$ in ethyl ether.

Molecular weights of the soluble polymers were measured by vapor pressure osmometry (VPO) (Table I). Degrees of polymerization of these polymers are generally low. The effect of the initiators on the conversion and the molecular weight may be interpreted by the nature of the counteranions of the oxonium ion. As shown in the time-conversion curves for the polymerization of $\mathbf{1 b}$ by the $\mathrm{SbCl}_{5}$ - and the $\mathrm{BF}_{3} \mathrm{THF}-$ ECH systems (see Figure 4), the polymerization with $\mathrm{BF}_{3}$ tends to be terminated at lower conver- sions than that with $\mathrm{SbCl}_{5}$. When $\mathrm{SbCl}_{5}$ was employed as a catalyst, the conversion increased with the reaction time. The molecular weight, however, did not increase as the reaction proceeded. These findings suggest that a chain-transfer reaction occurred in the polymerization with the $\mathrm{SbCl}_{5}$ catalyst.

In our previous study, ${ }^{11}$ the polymerizations of exo- and endo-2-t-butyl-7-oxabicyclo[2.2.1] heptanes using the $\mathrm{BF}_{3} \mathrm{THF}-\mathrm{ECH}$ system suffered from termination owing to proton elimination in 


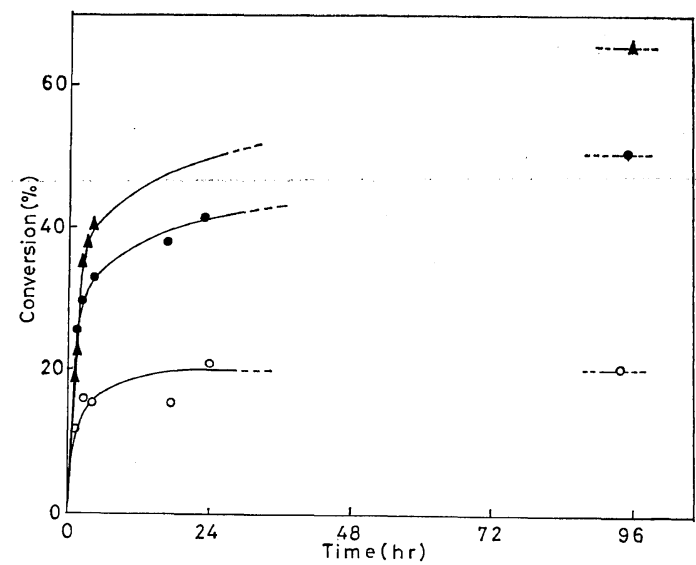

Figure 4. Conversion-time curve in the polymerization of $\mathbf{1 b}: \mathbf{\Delta}, \mathrm{SbCl}_{5}(4 \mathrm{~mol} \%),-20^{\circ} \mathrm{C} ; \bullet, \mathrm{SbCl}_{5}$ $(4 \mathrm{~mol} \%), 0^{\circ} \mathrm{C} ; \mathrm{O}, \mathrm{BF}_{3} \mathrm{THF}(4 \mathrm{~mol} \%), 0^{\circ} \mathrm{C}$; $\mathrm{ECH}$, $2 \mathrm{~mol} \%$.

their oxonium end; this resulted in low conversions since the protonic acid (such as $\mathrm{HBF}_{4}$ ) could not reinitiate these monomers. However, the polymerization in the present study may be reinitiated by a protonic acid such as $\mathrm{HSbCl}_{6}$ to give polymers of low molecular weights.

Increase of the polymerization temperature $(-20$ to $0^{\circ} \mathrm{C}$ ) lowers both the conversion and the molecular weight. Probably, at high temperature, another termination, in which the oxonium end reacts with the counteranion, occurred as well.

The stereochemistry of the propagation is an interesting subject of study. First, the propagation of 2,3-dimethyl monomers was examined by NMR spectroscopy of the product polymers. The monomers 1a and 1c can attack equally either of two bridgehead carbons of oxonium ions (4a and $4 c)$ to give poly(1a) and poly(1c), respectively. These are constructed of cyclohexane units of the same conformational structure (Scheme II).

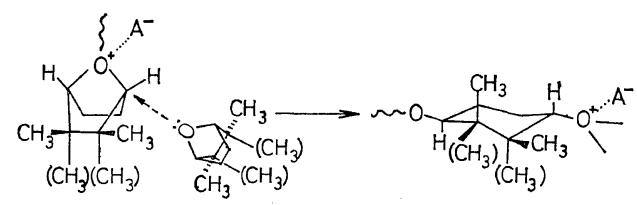

$4 a$ or $(4 c) 1 a$ or $(1 c) \quad \operatorname{poly}(1 a)$ or $(\operatorname{poly}(1 c))$

Scheme II

In the NMR spectrum of poly(1a) in trichloroethylene (Figure 5a), the two doublets at $\delta 0.9$ and

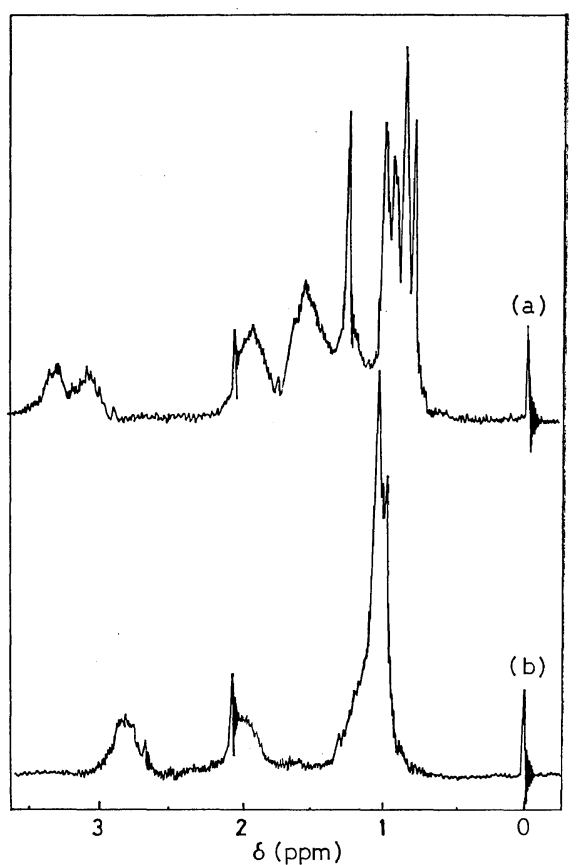

Figure 5. NMR spectra (100 MHz) of (a) poly(1a) and (b) poly(1b) in $\mathrm{CHClCCl}_{2}$.

$1.0 \mathrm{ppm}$ indicate the presence of two methyl groups located at axial and equatorial positions in its cyclohexane ring unit. The multiplets which are constructed of two bands centered at $\delta 3.1$ and $3.4 \mathrm{ppm}$ are assignable to two axial $\alpha$-methyne protons to the ether groups. The ratio of the integral intensity of these methyne protons to that of the other protons $(0.6-2.2 \mathrm{ppm})$ in the NMR spectrum of poly(1a) is about $1: 7$, which is close to the theoretical value $(1: 6)$.

In the polymerization of $\mathbf{1 b}$, two propagation processes at two bridgehead carbons ( $\mathrm{C}-1$ and $\mathrm{C}-4)$ of the oxonium ion $\mathbf{4 b}$ must be taken into consideration; i.e., the $S_{N} 2$ propagation at $\mathrm{C}-1$ yields polymer $\mathbf{5}$ and the one at C-4 polymer 7 (Scheme III).

The structure 5 is interconverted to the structure $\mathbf{6}$ in a conformational equilibrium, in which the conformation free-energy difference will favor 6 . This is because the cyclohexane ring unit in 6 has two equatorial methyl groups and two axial ether groups, whereas 5 has two axial methyl groups and two equatorial ether groups. Following the conformational study, ${ }^{12}$ it can be generalized that the 


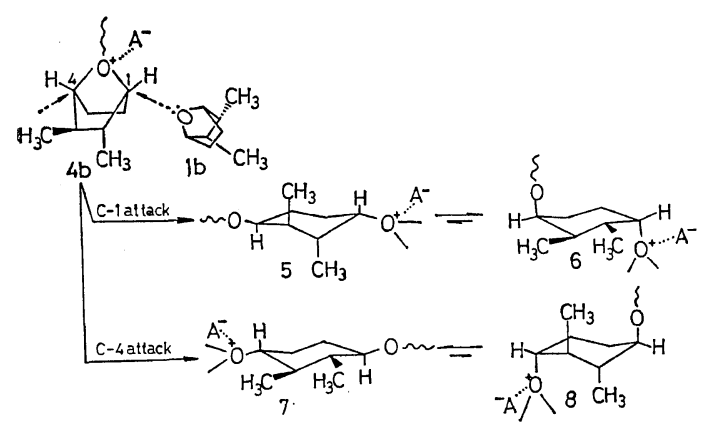

Scheme III

differences in conformational free energy are 1.5$2.1 \mathrm{kcal} / \mathrm{mol}$ for methyl and $0.6-0.75 \mathrm{kcal} / \mathrm{mol}$ for methoxy or $0.9-1.0 \mathrm{kcal} / \mathrm{mol}$ for ethoxy groups. Therefore, when the propagation occurs at $\mathrm{C}-1$, the main conformation of the polymer unit will be 6, in which $\alpha$-methyne protons are located at the equatorial position. On the other hand, the ring unit in 7 is conformationally a stable structure, in which all of the four substituents are at equatorial and $\alpha$-methyne protons are at axial positions. This problem was clarified by an NMR spectroscopic study of the polymer. The NMR spectrum shown in Figure $5 \mathrm{~b}$ indicates that the methyne proton takes the axial position, as shown by a multiplet signal centered at $\delta 2.9 \mathrm{ppm}$. This value of the chemical shift is higher than that of the axial protons of poly(1a). The NMR spectrum of poly(3b) showed a multiplet signal at $\delta 2.7 \mathrm{ppm}$ in $\mathrm{CDCl}_{3}$ for the axial methyne proton $\mathrm{H}_{2}$.

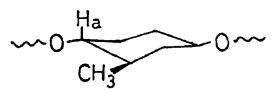

poly(3b)

In addition, the axial methyne proton of trans-2methylcyclohexanol resonates at $\delta 2.98 \mathrm{ppm}$ in $\mathrm{CCl}_{4}$, whereas the equatorial one of its $c i s$-isomer resonates at $\delta 3.75 \mathrm{ppm} .{ }^{13}$ From the above findings, it is concluded that the polymer unit of $\mathbf{1 b}$ takes 7 , but not 6 . This indicates that the steric effect of the endo-methyl substituent of the oxonium end $4 \mathrm{~b}$ toward the nucleophilic reaction with the monomer is higher than that of the exo-methyl substituent. From a molecular model of the monomer $1 \mathrm{~b}$, it is assumed that the back side of the $\mathrm{C}-1$ bridgehead carbon atom is blocked to a larger extent than that of the C-4 atom. The stereochemistry of the polymerizations of 2,5-dimethyl monomers is considered in a similar way. The NMR spectrum of poly(2a) coincided with that of poly(2c). The following scheme (Scheme IV) of propagation is taken to explain the above finding that the monomers $2 a$ and $2 c$ gave the same polymer.

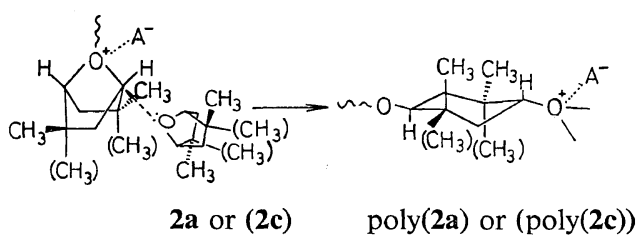

Scheme IV

The polymer of $\mathbf{2 b}$ was crystalline and insoluble in common organic solvents. Therefore, the direct analysis of the stereochemistry of the propagation of $\mathbf{2 b}$ could not be made.

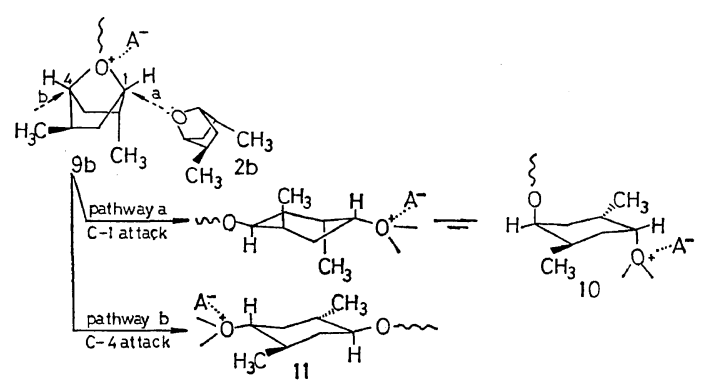

Scheme V

Nevertheless, a possible propagation through pathway $\mathbf{b}$ in the Scheme $\mathrm{V}$ is reasonably suggested on the basis of the fact that the back side of C-1 atom in $9 \mathrm{~b}$ is more blocked by steric hindrance of the endo-methyl substituent, as deduced from the result of the polymerization of $\mathbf{1 b}$. The polymer prepared from $\mathbf{2 b}$ through the pathway $\mathbf{b}$ has the structure 11, in which four substituents at 1, 2, 4, and 5 positions take equatorial positions.

In order to examine the nucleophilic reactivity of monomers, $\mathbf{2} \mathbf{a}, \mathbf{2} \mathbf{b}$ and $\mathbf{3 b}$ were subjected to cationic copolymerization with $3 \mathbf{a}\left(M_{1}\right)$. The reactivity ratios in these three systems were determined according to the Mayo-Lewis equation (Table II). The monomer nucleophilicities towards the common oxonium ion of $\mathbf{3 a}$ were compared 


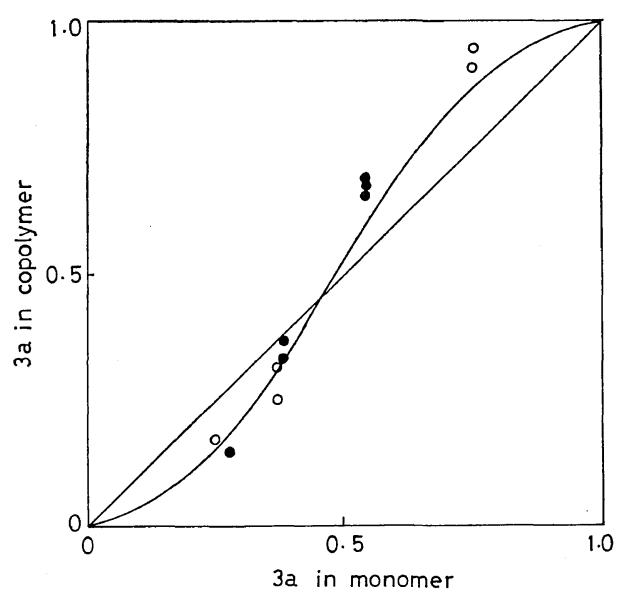

(a)

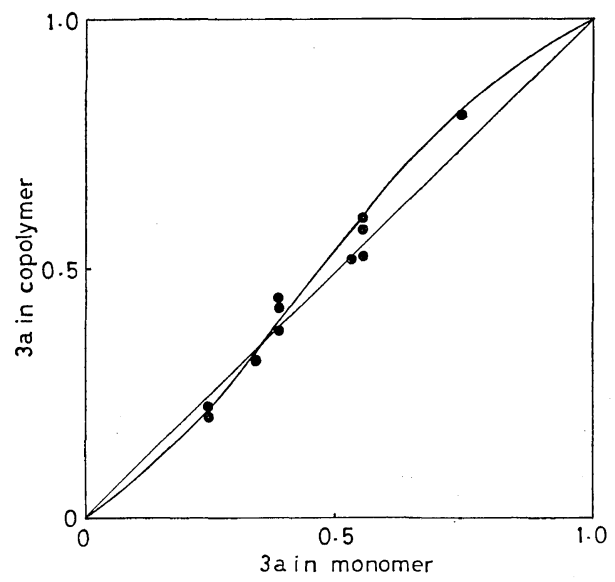

(b)

Figure 6. Copolymerization curves of $3 \mathbf{a}$ with the 2,5-dimethyl bicyclic ethers by $\mathrm{BF}_{3} \mathrm{THF}-\mathrm{ECH}$ in $\mathrm{CH}_{2} \mathrm{Cl}_{2}$.

(a) Copolymerization of $3 \mathbf{a}-\mathbf{2 a}$ at $-20^{\circ} \mathrm{C}(\bullet)$ and $0^{\circ} \mathrm{C}(\mathrm{O})$.

(b) Copolymerization of $\mathbf{3 a}-\mathbf{2} \mathbf{b}$ at $0^{\circ} \mathrm{C}$.

Table II. Cationic ring-opening copolymerizations of $3 a$ with $2 a, 2 b$, and $3 b$ by $\mathrm{BF}_{3} \mathrm{THF}-\mathrm{ECH}$ at $0^{\circ} \mathrm{C}$ in $\mathrm{CH}_{2} \mathrm{Cl}_{2}$

\begin{tabular}{cccccc}
\hline \multicolumn{2}{c}{ Comonomer } & & \multicolumn{2}{c}{ Reactivity ratio } & \multirow{2}{c}{$1 / r_{1}$} \\
\cline { 1 - 2 }$M_{1}$ & $M_{2}$ & & $r_{1}$ & $r_{2}$ & \\
\hline \multirow{3}{*}{$3 \mathrm{a}$} & $2 \mathrm{a}$ & & 6.0 & 5.5 & 0.17 \\
& 2b & & 2.0 & 1.5 & 0.50 \\
& 3b & & 0.9 & 1.4 & 1.11 \\
\hline
\end{tabular}

by the reciprocals of the reactivity ratios, $1 / r_{1}$. The $1 / r_{1}$ values increase in order of $\mathbf{2 a}<\mathbf{2} \mathbf{b}<$ $\mathbf{3 a}<\mathbf{3 b}$. This fact indicates that the presence of the exo-methyl group which is located at the front of the monomer is less favorable for its nucleophilicity. In the two series of the 2,3- and 2,5dimethyl monomers, it is assumed that the nucleophilicity increases in the order of exo,exo-< endo,exo-<endo,endo-isomers.

It is concluded that the reactivities of the dimethyl monomers in the present study are governed by the following factors: (1) the steric crowding around the bridgehead carbon atom of the propagating oxonium, (2) the monomer nucleophilicity, and (3) ring strain. The endo,exo-isomer will be the best situation among the dimethyl monomers. The position of the substituents in the monomer, of couse, affects its polymerization, and the exo,exo-2,3-dimethyl monomer gave a higher yield of polymer than the exo,exo-2,5-dimethyl monomer did. This may be interpreted as increased steric interaction of the substituents in the orientation of the 2,5-dimethyl monomer to its oxonium end.

Since the conversion should be influenced by the initiation and termination reactions, the direct comparison of monomer reactivity may be made by the kinetic study of the propagation reaction.

\section{EXPERIMENTAL}

\section{Materials}

exo,exo-, endo,exo-, and endo,endo-2,3-Dimethyl7-oxabicyclo[2.2.1]heptanes (1a, 1b, and 1c). Dimethylaminophenol, which was prepared from 2,3-dimethylphenol (100 g, $0.82 \mathrm{~mol}$ ) according to the ordinary method described by Fieser, ${ }^{14}$ was dissolved in a mixture of $45 \mathrm{ml}$ of concentrated $\mathrm{H}_{2} \mathrm{SO}_{4}$ and $890 \mathrm{~m} l$ of water, and filtered through a pad of active carbon. The filtrate was added to a suspension of $\mathrm{MnO}_{2}$ (assay $65 \%$ ) in a mixture of concentrated $\mathrm{H}_{2} \mathrm{SO}_{4}$ and $890 \mathrm{ml}$ of water below $45^{\circ} \mathrm{C}$ and stirred at $45-50^{\circ} \mathrm{C}$ for $1 \mathrm{~h}$. Yellow crystals of 2,3-dimethylbenzoquinone was separated from the reaction mixture by steam distillation at $40-42^{\circ} \mathrm{C}$ under the reduced pressure of $70 \mathrm{mmHg}$ : $\mathrm{mp} 54.5-57.5^{\circ} \mathrm{C}$ [lit. ${ }^{7} 54.5-55.5^{\circ} \mathrm{C}$ ], yield of $70 \%$ based on the dimethylphenol. The benzoquinone was reduced with $\mathrm{Zn}$ powder in aqueous acetic acid to give 2,3-dimethylhydroquinone in a $90-\%$ yield: $\operatorname{mp} 221.5-224^{\circ} \mathrm{C}$ [lit. ${ }^{7}$ 
$221^{\circ} \mathrm{C}$. Catalytic hydrogenation of the hydroquinone $(50 \mathrm{~g})$ was carried out with Raney $\mathrm{Ni}$ (W-2) $(15 \mathrm{ml})$ in $\mathrm{CH}_{3} \mathrm{OH}(100 \mathrm{ml})$ at $140-150^{\circ} \mathrm{C}$ under initial $\mathrm{H}_{2}$ pressure of $110 \mathrm{~atm}$. The solution was freed from the catalyst by filtration. Removal of the solvent gave a residue of an isomeric mixture of 2,3-dimethylcyclohexane-1,4-diols almost quantitatively. The diols $(102 \mathrm{~g})$ was mixed with $153 \mathrm{~g}$ of activated alumina (after being heattreated at $450-500^{\circ} \mathrm{C}$ for $4 \mathrm{~h}$ ) and the mixture was heated gradually to $260^{\circ} \mathrm{C}$. The volatile fraction was distilled to a trap cooled in icewater under reduced pressure $(90-100 \mathrm{mmHg})$. The distillate was extracted with ether and dried over anhydrous $\mathrm{K}_{2} \mathrm{CO}_{3}$. After removal of the solvent, a residue was separated onto the desired bicyclic ethers, $\mathbf{1 b}$, $1 \mathrm{a}$, and 1c, in yields of $16.5,11.2$, and $1.4 \%$, respectively, by means of a fractional distillation using a column $(100 \mathrm{~cm})$ equipped with a spinning band. Their boiling points were 150-151, 156158 , and $158-162^{\circ} \mathrm{C}$; their purities were about $95 \%$ by gas-chromatographic analyses. Final purification of the ethers was successfully achieved with High Vacuum Oil or PEG 20M on Celite (60-80 mesh) at $100^{\circ} \mathrm{C}$ under $\mathrm{H}_{2}$ pressure of $1.0 \mathrm{~kg} / \mathrm{cm}^{2}$. The monomers had purities above $99 \%$. Their NMR spectra are shown in Figures 1a-1c. Elemental analyses for $\mathbf{1 a}$ and $\mathbf{1 b}$ were as follows:

Anal. Calcd for $\mathrm{C}_{8} \mathrm{H}_{14} \mathrm{O}: \mathrm{C}, 76.14 ; \mathrm{H}, 11.18$. Found: C, 76.23; H, 11.07, and C, 75.95; H, 11.20, respectively, for $\mathbf{1 a}$ and $\mathbf{1 b}$. The analytical value for 1c could not be determined because its weight decreased gradually during weighing of a sample. exo,exo-, endo,exo-, and endo,endo-2,5-Dimethyl7-Oxabicyclo[2.2.1] heptanes (2a, $\mathbf{2 b}$, and $\mathbf{2 c}$ ). These were synthesized by procedures similar to those for 2,3-dimethyl monomers, with the exception of the oxidation procedure. The oxidation of 2,5dimethylaminophenol to the corresponding benzoquinone was carried out with $\mathrm{FeCl}_{3} \cdot 6 \mathrm{H}_{2} \mathrm{O}$ and hydrochloric acid to yield a yellow crystal: $\mathrm{mp}$ $121.3-123.5^{\circ} \mathrm{C}$ [lit. $\left.{ }^{15} 123-125^{\circ} \mathrm{C}\right]$. The catalytic hydrogenation of 2,5-dimethylhydroquinone, $\mathrm{mp}$ $213-214^{\circ} \mathrm{C}$ [lit. ${ }^{16} 212-213^{\circ} \mathrm{C}$ ], followed by treatment with active alumina produced $\mathbf{2 a}, \mathbf{2 b}$, and $\mathbf{2 c}$ in yields of $9.6,4.9$, and $3.2 \%$; their boiling points were $146-148,152-154$, and $157-159^{\circ} \mathrm{C}$, respectively. By the preparative gas chromatography, they were purified to above $99 \%$. Their NMR spectra are shown in Figures $2 a-2 c$.
Anal. Calcd for $\mathrm{C}_{8} \mathrm{H}_{14} \mathrm{O}: \mathrm{C}, 76.14 ; \mathrm{H}, 11.18$. Found: C, 76.06; H, 11.34 for 1a, C, 76.39; H, 11.19 for $1 \mathbf{b}$ and C, 75.87; H, 10.91 for $\mathbf{1 c}$.

\section{Initiators and Solvents}

$\mathrm{BF}_{3}$ THF complex was prepared according to the literature, ${ }^{17}$ bp $88^{\circ} \mathrm{C}(11 \mathrm{~mm}) . \mathrm{SnCl}_{4}, \mathrm{SbCl}_{5}$, and $\mathrm{FeCl}_{3}$ were purified by distillation or sublimation under nitrogen. $\mathrm{FeCl}_{3}$ was dissolved in dry ether, and the other salts in $\mathrm{CH}_{2} \mathrm{Cl}_{2}$. $\mathrm{ECH}$ and $\mathrm{SOCl}_{2}$ were distilled over $\mathrm{CaH}_{2}$ and $\mathrm{P}_{2} \mathrm{O}_{5}$, respectively, under a nitrogen atmosphere. Solvent $\mathrm{CH}_{2} \mathrm{Cl}_{2}$ was purified according to the procedure described previously. ${ }^{18}$ Ether was purified by the ordinary method. ${ }^{19}$

\section{Polymerization Procedure}

The polymerization was carried out under dry nitrogen. The monomer was weighed in a reaction tube, which was dried and flushed with $\mathrm{N}_{2}$ gas, and the catalyst and cocatalyst or promotor solutions were added successively into the monomer at the desired temperature. The polymerization was quenched by addition of $0.5-N$ sodium methoxide in methanol, and the amount of the remaining monomer was determined by gas chromatography after adding dioxane as an internal standard $(3 \mathrm{~mm} \times 3 \mathrm{~m}$ glass column packed with PEG $6000 /$ Shimalite $\mathrm{F}$; $100^{\circ} \mathrm{C}$; carrier gas, $\mathrm{N}_{2}$; detector, FID). The polymer solution was extracted with $\mathrm{CH}_{2} \mathrm{Cl}_{2}$, washed successively with aqueous $\mathrm{NaOH}$ and water, and dried over $\mathrm{K}_{2} \mathrm{CO}_{3}$. Evaporation of the solvent and the unreacted monomer from the solution left a polymer. Poly(1b) was purified further by reprecipitation using $\mathrm{CH}_{2} \mathrm{Cl}_{2}$ (solvent)-methanol (precipitant), and $\operatorname{poly}(2 a)$ and poly(2c) were purified by methanolwater. The insoluble polymers, poly(1a) and poly(2b), were separated from the polymerization mixture by centrifuging, washed with $3-\mathrm{NHCl}$ and water successively, and dried in vacuo. The monomer reactivity ratios were determined by the curve fitting method (Figure 6).

\section{NMR and X-Ray Measurements}

Nuclear magnetic resonance spectra were determined on a PS-100 (Jeol Ltd.) at $23^{\circ} \mathrm{C}$. X-ray diffraction used $\mathrm{Cu}-\mathrm{K} \alpha$ rays on a SG-7 (Rigaku Denki). 


\section{REFERENCES}

1. T. Saegusa, M. Motoi, S. Matsumoto, and $H$. Fujii, Macromolecules, 5, 233 (1972).

2. T. Saegusa, S. Matsumoto, M. Motoi, and H. Fujii, Macromolecules, 5, 236 (1972).

3. T. Saegusa, M. Motoi, S. Matsumoto, and H. Fujii, Macromolecules, 5, 815 (1972).

4. J. Kops and H. Spanggaard, Makromol. Chem., 151, 21 (1972).

5. L. I. Smith and J. W. Opie, J. Org. Chem., 6, 427 (1941).

6. L. F. Fieser and M. I. Ardao, J. Am. Chem. Soc., 87, 774 (1956).

7. J. H. Emerson and L. I. Smith, J. Am. Chem. Soc., 62, 142 (1940).

8. R. T. Arnold and H. E. Zaugg, J. Am. Chem. Soc., 63, 1317 (1941).

9. N. L. Allinger, J. Am. Chem. Soc., 79, 3445 (1957).

10. A. F. Bedford, A. F. Beezer, C. T. Mortimer, and H. D. Springall, J. Chem. Soc., 3823 (1963).

11. T. Saegusa, M. Motoi, and H. Suda, Macromolecules, 9, 213 (1976).
12. E. Eliel, N. L. Allinger, S. Anggal, and G. A. Morrison, "Conformational Analysis," Interscience Publishers, John Wiley and Sons, Inc., New York, N. Y., 1965, p 44.

13. E. L. Eliel, M. H. Gianni, Th. H. Williams, and J. B. Stothers, Chem. Abstr., 58, 2043B (1963); Tetrahedron Lett., 741 (1962); J. I. Musher, J. Chem. Phys., 35, 1159 (1961).

14. L. F. Fieser, "Organic Syntheses," Coll. Vol. II, John Wiley and Sons, Inc., New York, N. Y., 1943, p 39.

15. L. I. Smith and J. W. Opie, J. Org. Chem., 6, 427 (1941).

16. L. I. Smith and J. Nichols, J. Am. Chem. Soc., 65, 1742 (1943).

17. R. C. Osthoff, C. A. Brown, and J. A. Hawkins, J. Am. Chem. Soc., 73, 5480 (1951).

18. T. Saegusa and S. Matsumoto, Macromolecules, 1, 442 (1968).

19. J. A. Riddick and E. E. Toops, Jr., "Organic Solvents," Interscience Publishers, New York, N. Y., 1955, p 367. 